\title{
VALORISATION OF TAINTED BOAR MEAT IN PATTIES, \\ 2 FRANKFURTER SAUSAGES AND COOKED HAM BY MEANS OF TARGETED DILUTION, COOKING AND SMOKING
}

Lieselot Y. Hemerycka,1, Jella Wautersa,1, Lore Dewulfb, Anneleen I. Decloedta, Marijke Aluwéc, Stefaan De Smetd, Ilse Fraeyeb,2, Lynn Vanhaeckea,e,2,*

a Laboratory of Chemical Analysis, Department of Veterinary Public Health and Food Safety, Faculty of Veterinary Medicine, Ghent University, Salisburylaan 133, B-9820 Merelbeke, Belgium.

b Research Group for Technology and Quality of Animal Products, Department $\mathrm{M}_{2} \mathrm{~S}$, member of Leuven Food Science and Nutrition Research Centre (LFoRCe), KU Leuven Ghent Technology Campus, Gebroeders De Smetstraat 1, B-9000 Ghent, Belgium.

c Animal Sciences Unit, Institute of Agricultural and Fisheries Research (ILVO), Scheldeweg 68, B-9090 Melle, Belgium.

d Laboratory for Animal Nutrition and Animal Product Quality, Department of Animal Sciences and Aquatic Ecology, Faculty of Bioscience Engineering, Ghent University, Coupure Links 653, B-9000 Ghent, Belgium.

e Institute for Global Food Security, School of Biological Sciences, Molecular Biosciences, Queen's University, University Road, Belfast, Northern Ireland.

${ }_{1}$ Equally contributing first authors

2 Equally contributing senior authors

* Corresponding author: Lynn.Vanhaecke@UGent.be (+32 26474 57). 
27 Because of the need to abolish the castration of piglets without anaesthesia/analgesia,

28 the pig industry is searching for a mode of action for the valorization of meat with boar 29 taint, an off-odour in entire male pigs. Carcasses with boar taint were selected by 30 means of sensory and chemical analysis, after which patties with different levels of 31 tainted boar meat were produced, as well as cooked ham and Frankfurter sausages 32 using different smoke condensates and cooking temperatures. For these products, i.a. 33 orthonasal and retronasal boar taint odour were assessed by a trained expert panel. 34 The results offer guidance regarding dilution of tainted meat (with $<400 \mu \mathrm{g} \mathrm{kg-1}$ 35 androstenone if skatole is low or $<200 \mu \mathrm{g} \mathrm{kg}-1$ androstenone in concurrence with $\geq 37$ $36 \mu \mathrm{g} \mathrm{kg}-1$ skatole) and the potential application of smoke condensates (e.g. Rudinsmoke 37 C for sausages and Smokez LFBN for ham) as promising boar taint masking 38 strategies.

39

40 Keywords

41 Androstenone, Boar taint, Consumer acceptance, Indole, Masking strategy, Pork, 42 Skatole 


\section{$441 . \quad$ INTRODUCTION}

45 In light of welfare concerns, there is an industry-wide incentive to ban the surgical castration of male piglets without anaesthesia and/or analgesia (Declaration of Brussels, 2010). The alternatives include castration with anaesthesia and/or pain relief, immunocastration and/or rearing of entire male pigs. The latter demonstrates several distinct advantages for farmers, including a better feed to gain ratio as well as the production of carcasses with a higher percentage of lean meat (Aluwe et al., 2009).

51 Nevertheless, the rearing of entire males for pork production remains problematic because of the potential occurrence of boar taint, an off-odour in meat and adipose tissue. Boar taint is described as a sweaty, urine- and/or fecal-like (orthonasal and retronasal) odour that can give cause to consumer dissatisfaction (Claus, Weiler, \& Herzog, 1994; Lundstrom, Matthews, \& Haugen, 2009). Indole (IND), skatole (SK) and androstenone (AEON) are considered to be the three main boar taint contributing compounds (Aluwe, Tuyttens, \& Millet, 2015), although the incidence and perception of boar taint is rather complex and not fully understood to date. About $99 \%$ of consumers can perceive IND and SK, but not AEON, of which perception roughly ranges from 30 to $80 \%$ depending on e.g. age, gender, genetic predisposition and country of origin (Bekaert et al., 2011; Wysocki \& Beauchamp, 1984). Considering the pig sector has stipulated that the valorisation of tainted boar meat is part of the terms and conditions for imposing the ban of surgical castration, there is an urgent need for more in-depth experimentation and knowledge on boar taint reducing and/or masking pork production processes. There are several strategies that may facilitate consumer acceptance of tainted boar meat including smoking, fermenting, dry-curing, cooking, seasoning and diluting. The latter, i.e. diluting, is a fairly straightforward strategy that can easily be implemented for certain processed meat products like e.g. patties and a large variety of sausages by blending raw material 
71 potential of dilution in order to increase consumer acceptance is determined by several

72 factors including the severity of the taint and the type of product (Babol \& Squires, 73 1995; Meier-Dinkel et al., 2016). Regarding smoking and cooking, the potential of both 74 of these strategies has been demonstrated in a number of studies - e.g. for the 75 production of Frankfurter sausages - although further optimization of the duration of 76 cooking temperature, smoking cycles, penetration of smoke, and type of smoke is 77 prerequisite (Kallas, Martínez, Panella-Riera, \& Gil, 2016; Lundstrom et al., 2009; 78 Martinez et al., 2016; Meier-Dinkel et al., 2016; Stolzenbach, Lindahl, Lundström, 79 Chen, \& Byrne, 2009). Therefore, to add to the current knowledge on boar taint 80 masking and reducing strategies in response to the current needs of the pig industry, 81 this paper focusses on (1) the optimisation of blending percentage in pork patties, 82 aiming to define acceptable IND, SK and AEON levels, (2) investigation of the masking 83 potential of specific smoke condensates for the production of restructured cooked ham 84 and sausages, alongside (3) experimentation with cooking temperature in relation to 85 product acceptance by a trained boar taint expert panel. As such and more specifically, 86 the following hypothesis will be addressed; blending of meat and fat with and without 87 boar taint, cooking as well as addition of smoke condensates can significantly mask 88 and/or reduce (the perception of) boar taint and facilitate the consumption of tainted 89 boar meat in patties, Frankfurters and restructured cooked ham.

90 


\section{MATERIAL AND METHODS}

92

93

94

95

96

97

98

99

100

101

102

103

104

105

106

107

108

109

110

111

112

113

114

115

116

A schematic overview of the experimental setup of this work is provided as supplementary information figure 1.

\subsection{Training of boar taint experts}

Trained panelists are better capable and thus more sensitive of detecting deviations or alterations in meat products compared to consumers (Font-i-Furnols, 2012; Verplanken, Wauters, Vercruysse, Aluwé, \& Vanhaecke, 2017), and therefore, individuals sensitive to boar taint (as assessed using a triangle test) were trained to sniff and rank different levels (0 - $0.5-5-50 \mu \mathrm{g}$ - -1$)$ of SK and AEON (the two main (known) boar taint contributing compounds) as well as to perceive boar taint compounds upon singeing of tainted fat, which has been described in detail previously (Wauters, Vercruysse, Aluwé, Verplanken, \& Vanhaecke, 2016). Hence, for a more detailed description of the training of boar taint experts as well as sensory evaluation of boar taint meat products (discussed in 2.4.2), the authors refer to Wauters et al. (Wauters, Verplanken, Vercruysse, Ampe, Aluwé, \& Vanhaecke, 2017).

\subsection{Selection of tainted carcasses (and meat cuts)}

2.2.1. Sensory analysis at-line

Boar taint prevalence (yes/no) in freshly slaughtered boars was assessed at a local Belgian abattoir (Debra Meat; Exportslachthuis, Tielt) by 2 alternating trained experts using the soldering iron method (Bekaert et al., 2013). In doing so, a total of 45 moderately to strongly tainted carcasses were selected, of which a neck fat sample was collected and transported to the lab (Laboratory for Chemical Analysis, cooled transport). To permit multiple experiments, the described selection procedure was performed twice (during fall 2017 and early summer 2018). Experiments with meat 
117 from carcasses that were selected during the first selection procedure will be referred

118 to as 'trial 1', and the second as 'trial 2'.

119

120

121

122

123

124

125

126

127

128

129

130

\subsubsection{Chemical analysis}

\subsubsection{Reagents and chemicals}

Reference standards indole (IND, 2,3-benzopyrrole, CAS: 120-72-9), skatole (SK, 3methylindole, CAS: 83-34-1) and androstenone (AEON, 5a-androst-16-ene-3-one, CAS: 18339-16-7), as well as internal standards 2-methylindole (2-MID, CAS: 95-205) and androstadienedione (ADD, 1,4-androstadiene-3,17-dione, CAS: 897-06-3) were purchased from Sigma Aldrich (St. Louis, MO, USA). Stock solutions were prepared in methanol, at a concentration of $1 \mathrm{mg} \mathrm{ml}-1$.

Reagents for extraction purposes (VWR International, Merck, Darmstadt, Germany) and UHPLC-MS applications (Fisher Scientific, Leicestershire, VS) were of analytical and of MS-grade. Solid phase extraction (SPE) columns (Oasis HLB, 3 cc $60 \mathrm{mg}$ ) were purchased from Waters Corporation (Milford, US).

\subsubsection{Sample preparation}

Sample clean-up and extraction was performed according to the protocol by Bekaert et al. (Bekaert et al., 2012a). In brief, $2 \mathrm{~g}$ of neck fat was melted in the microwave (3 min at $300 \mathrm{~W}$ ), after which methanol was added. Extraction was enhanced by putting the samples in a hot water bath for 60 min. Afterwards, sample preparation continued with a clean-up step through freezing $\left(60 \mathrm{~min}\right.$ at $\left.-20^{\circ} \mathrm{C}\right)$, centrifugation and solid phase extraction (Oasis HLB, 3 cc $60 \mathrm{mg}$ ).

For quantification purposes, calibration curves were prepared by spiking fresh blank neck fat (from a sow) with a standard mixture of IND, SK and AEON $(0,10,25,50,75$, $100,250,500,750,1000,2000,3000,4000$ and $5000 \mu g$ kg-1). Prior to extraction of 
143

144

boar samples and calibration curve samples, internal standards 2-MID and ADD were added at a concentration of $500 \mu \mathrm{g} \mathrm{L-1.}$

\subsubsection{UHPLC-HRMS analysis}

Chromatographic separation and detection was achieved by means of Ultra High Performance Liquid Chromatography (UHPLC) coupled to High Resolution Mass Spectrometry (HRMS) using an Exactive orbitrap instrument (Thermo Fisher, San José, USA). A detailed description of this method can be consulted in the work by Bekaert et al. (Bekaert et al., 2012b).

\subsubsection{Selection, processing and storage of carcasses and meat} Following sensory analysis at-line, the 45 selected moderately to strongly tainted carcasses were re-analyzed sensorially, enabling assessors $(n=3)$ to assign a sensory score from 0 to 4 ( $0=$ no boar taint, $4=$ very strong boar taint). After chemical analysis, and thus based on the results of the chemical and final sensory analysis combined, a final selection of 4 carcasses (as strong as possible and, if possible, different types of 'tainters') was made. After final selection, meat cuts from the 4 selected boar carcasses and gilts (kindly provided by Debra Meat, Exportslachthuis, Tielt, Belgium) were prepared in the slaughterhouse and transported $\left(4^{\circ} \mathrm{C}\right)$ to the Research Group for Technology and Quality of Animal Products lab (Ghent, Belgium). This included boneless hams, lean pork meat, belly fat, pork shoulder, back fat and jowl fat.

Pork shoulder, back and jowl fat from the selected boars were chopped using a guillotine cutter (Magurit Gefrierschneider $\mathrm{GmbH}$, Remscheid, Germany) and mixed thoroughly to generate one single batch for each raw material for the production of the sausages (2.3.3). In addition, lean pork meat and belly fat were also chopped using the guillotine cutter and homogenized to generate one batch of each raw material, 
which was to be used for the production of patties (2.3.1). Similarly, a homogeneous batch of lean pork meat and belly fat from gilt was generated as well (for the production of the patties). Following this, the boneless hams (selected for restructured ham production (2.3.2)) and homogenized batches of meat and fat were vacuum packed (Webomatic Maschinenfabrik $\mathrm{GmbH}$, Bochum, Germany) and stored at $-20^{\circ} \mathrm{C}$ until the experimental production of pork products took place.

\subsection{Production of pork products}

\subsubsection{Pork patties: effect of dilution}

On the day of patty production, the homogenized batches of lean pork cuts and belly fat were defrosted. Patties with $0,10,20,40,60,80$ and $100 \%$ of tainted meat (and fat, in a $70 / 30$ ratio), complemented with $100,90,80,60,40,20$ and $0 \%$ of (nontainted) gilt meat (and fat, in a 70/30 ratio) respectively, were produced simply by adding different ratios of boar taint meat and gilt meat, after which this meat and fat mixture was minced through a 8-mm steel plate using a meat mincer (Minerva Omega Group S.r.l., Bologna, Italy). Following this, the ground meat and fat were mixed with white pepper ( $2 \mathrm{~g} / \mathrm{kg}$, provided by Solina, Eke-Nazareth, Belgium), sodium chloride (13 g/kg, provided by Solina, Eke-Nazareth, Belgium), egg (1 egg/kg, bought in a local store) and bread crumbs (50 $\mathrm{g} / \mathrm{kg}$, bought in a local store). The mix was then minced a second time through a $4-\mathrm{mm}$ steel plate, and patties $(130 \mathrm{~g})$ were shaped using a household patty mould. The patties were stored at $4{ }^{\circ} \mathrm{C}$, until the sensory test took place later that day.

\subsubsection{Restructured ham: effect of smoke condensate}

Three preparations of restructured cooked ham were made, with each preparation having its own brine composition (see supplementary table 1) through the addition of none (brine 1) or 1 out of 2 selected smoke condensates Smokez LFBN (brine 2) and 
Smokez BN-9 (brine 3). The dextrose, nitrite curing salt, phosphate, sodium ascorbate

198 and yeast extract were provided by Solina (Eke-Nazareth, Belgium). The smoke 199 products, i.e. Smokez LFBN and Smokez BN-9, were provided by Red Arrow 200 (Apeldoorn, Netherlands).

201 Boneless hams were defrosted $\left(30 \mathrm{~h}\right.$ at $\left.4^{\circ} \mathrm{C}\right)$, trimmed of external fat and connective 202 tissue and ground (Minerva Omega Group S.r.l., Bologna, Italy) through a 4-mm steel 203 plate. The meat of the 4 selected boars (10 kg in total) was tumbled (Rühle $\mathrm{GmbH}$, 204 Grafenhausen, Germany) for 180 min at $7 \mathrm{rpm}$ and $90 \%$ vacuum following the addition 205 of the brine $(2.5 \mathrm{~kg}$ ) (see supplementary table 1). Thereafter, the meat was stuffed 206 (Industrial Fuerpla, Valencia, Spain) in polymer casings with a diameter of $90 \mathrm{~mm}$ 207 (Solina, Eke-Nazareth, Belgium), clipped (Tipper Tie, Glinde, Germany) and cooked 208 for $3 \mathrm{~h} 30 \mathrm{~min}$ at $75^{\circ} \mathrm{C}$ in a climate chamber (Kerres Anlagensysteme $\mathrm{GmbH}$, 209 Backnang, Germany), and finally cooled to and stored at $4{ }^{\circ} \mathrm{C}$.

2.3.3. Frankfurter sausages: effect of smoking method and/or cooking temperature

213 Starting from the homogenized batch of pork shoulder, back and jowl fat, Frankfurter 214 sausages were made, whereby different smoking methods and/or cooking 215 temperatures were applied (table 1). Cooking programs can be consulted in 216 supplementary information table 2 and 3.

217 Pork meat (400 g/kg) was vacuum chopped together with ice $(250 \mathrm{~g} / \mathrm{kg})$, phosphate (3 $218 \mathrm{~g} / \mathrm{kg}$ ) and nitrite curing salt (17 $\mathrm{g} / \mathrm{kg})$ in a bowl cutter (Kilia, Neumünster, Germany) 219 until the meat batter reached a temperature of $5^{\circ} \mathrm{C}$. Next, back fat $(200 \mathrm{~g} / \mathrm{kg})$ and jowl 220 fat $(150 \mathrm{~g} / \mathrm{kg})$ were added to the meat batter together with dextrose $(5 \mathrm{~g} / \mathrm{kg})$, white 221 pepper $(2 \mathrm{~g} / \mathrm{kg})$, mace $(0.5 \mathrm{~g} / \mathrm{kg})$, cardamom $(0.5 \mathrm{~g} / \mathrm{kg})$, sodium ascorbate $(0.5 \mathrm{~g} / \mathrm{kg})$ 222 and glutamate $(0.5 \mathrm{~g} / \mathrm{kg})$ and vacuum chopped until the temperature reached $14{ }^{\circ} \mathrm{C}$. 223 In case smoke condensate was added to the meat batter (for sausage 7 and 8 , see 
224 table 1), this was done together with the spices. After the cutting process, the meat 225 batter was stuffed (Industrial Fuerpla, Valencia, Spain) in collagen casings with a 226 diameter of $22.5 \mathrm{~mm}$ (Viscofan, Tajonar-Navara, Spain). In case of sausage 4 to 6 227 (see table 1), the sausages were drenched in smoke condensate solutions. Sausages 228 were pasteurized in a climate chamber (Kerres Anlagensysteme GmbH, Backnang, 229 Germany) according to the conditions described in supplementary table 2 (sausage 12303 ) and 3 (sausage 4-8). After pasteurization, sausages were cooled to $4{ }^{\circ} \mathrm{C}$. Finally, 231 sausages were vacuum packed (Webomatic Maschinenfabrik GmbH, Bochum, 232 Germany) and stored at $4{ }^{\circ} \mathrm{C}$.

233 Phosphate, nitrite curing salt, dextrose, white pepper, mace, cardamom, sodium 234 ascorbate and glutamate were provided by Solina (Eke-Nazareth, Belgium). The 235 smoke condensates Rudinsmoke B, C or D were provided by Ruitenberg (Twello, 236 Netherland) and Smokez poly C-10 and Smokez supreme poly C by Red Arrow 237 (Apeldoorn, Netherland).

238

\subsection{Sensory and chemical evaluation of pork products}

241 Meat samples were served per product, one by one, in randomized order within, but 242 not across panelists. Cooking and preparations for serving of meat products were 243 performed in a room separate from the evaluation room to avoid possible interference 244 and bias due to e.g. the perception of baking odours. Patties and restructured ham 245 (when tasted warm) were baked on contact grills (2000W) greased with sunflower oil. 246 To avoid contamination, each product was prepared on a separate grill. Frankfurters 247 were re-heated in hot water for 4 to 5 minutes, using separate cooking pots for different 248 types of sausages. Core temperature was monitored until $70^{\circ} \mathrm{C}$, after which all heated 249 products were cut into smaller pieces and served hot to the experts (with a lid). 250 Frankfurter sausages and restructured ham were also tasted cold. In this case, they 
251 were simply chopped in individual portions and served as such. There was a maximum 252 of 14 samples per session.

\subsubsection{Sensory evaluation}

255 The orthonasal odour (further referred to as 'smell' in light of simplicity) and retronasal 256 odour (further referred to as 'taste'), and several other characteristics of the produced 257 pork products were evaluated by a minimum of 7 trained experts (max. 10) in duplicate, 258 i.e. on two separate non-consecutive days ('day 1' and 'day 2').

259 Sensory evaluation was performed under standardized circumstances, as has already 260 been described in detail by Wauters et al. (Wauters et al., 2017), as well as previously 261 in 2.4.1 Meat cooking and serving. More specifically, evaluation by panelists covered 262 general (overall) smell, boar taint smell, general (overall) taste and boar taint taste of 263 the meat product under investigation on a $150 \mathrm{~mm}$ scale; with e.g. 0 representing the 264 total absence and 150 representing the very strong presence of the described attribute. 265 In addition, the overall sensory quality and taste (tastiness), as well as the 266 consumability or acceptance of the product were assessed and scored. The 267 consumability ('overall acceptance') of each sample was scored from 0 to 10 , with 0 268 being non-consumable and 10 perfectly consumable. Products were also ranked 269 according to preference and boar taint perception. Regarding preference, '1' 270 represented the most favored product, with a higher number (lower ranking) correlating 271 with an increasingly less favored product. With regard to boar taint perception; ' 1 ' was 272 reserved for the product with least strong boar taint, as perceived by the experts. More 273 details on utilized attributes and scales are provided in supplementary information 274 tables 4 and 5. Besides general smell, boar taint smell, general taste, boar taint taste, 275 general tastiness, consumability and ranking according to preference and boar taint, 276 product texture (i.e. toughness/tenderness (ham and Frankfurters), juiciness (all 3 277 products), grain/consistency (Frankfurters and hamburgers) and greasiness 
278 (hamburgers)) as well as product specific characteristics (i.e. salty flavor (ham), smoky 279 flavor (Frankfurters), pink color (ham and Frankfurters), marbling (ham) and color 280 homogeneity (ham and Frankfurters)) were assessed as well (but will not be discussed 281 as this did not reveal relevant findings).

\subsubsection{Chemical analysis}

284 Analysis of SK, IND and AEON in all products (i.e. in raw patties post production, in 285 pre and post cooking Frankfurters and ham) was performed as described previously 286 in section 2.2.2, and according to Wauters et al. (Wauters et al., 2017).

\subsection{Data analysis and interpretation}

289 Initial data processing and interpretation of the chemical analysis of fat and meat was 290 performed using Xcalibur 2.1.0. Statistical interpretation of all data was performed 291 using SPSS 25. Since assumptions for ANOVA regarding independence of 292 observations and normally distributed data could not be met, rating of pork products 293 was assessed using a non-parametric Friedman Test, followed by a Wilcoxon Signed 294 Ranks Test. Correlations were assessed using Spearman's rank. A significance level 295 of 0.05 was taken into account. 


\section{RESULTS AND DISCUSSION}

\subsection{Boar taint levels in neck fat from selected boars}

298 For both the first and second trial of experimentation with dilution of tainted boar meat 299 through mixing with gilt meat, four tainted carcasses were selected based on sensory 300 analysis and IND, SK and AEON levels in fresh neck fat, of which detailed results can 301 be consulted in supplementary information table 6 . Overall, the boars that could be 302 selected for the second trial demonstrated a more severe taint.

\subsection{Patties}

\subsubsection{Trial 1}

306 In the first trial, 7 different patties with $0,10,20,40,60,80$ or $100 \%$ of tainted boar meat were produced and evaluated. All trends regarding perceived smell, taste and

308 tastiness can be consulted in figure 1, whilst detailed data (means and standard errors) 309 and correlations between sensory parameters and scores in relation to boar meat percentage can be consulted in supplementary information tables 7 and 8 (the score

311 and ranking interpretation sheet can be consulted in supplementary information table $3125)$.

313 A significant positive correlation between boar meat \% and boar taint taste and smell 314 perception could be retrieved, in contrast to an inverse correlation with general 315 tastiness and assigned product score. However, besides these correlations, the more 316 important question to ask is; up until which level of IND, SK and/or AEON is the product 317 still acceptable for consumption? In this context, it could be observed that tainted boar 318 meat \% indeed affected general tastiness $(P<0.05)$, with a significantly lower value 319 for patties containing 60 or $80 \%$ of tainted meat in comparison to patties with 0,10 , 32020 and $40 \%$ of tainted meat. There is a distinctively lower appreciation of patties from $32160 \%$ mixing onwards, which aligns with the more pronounced perception of boar taint 322 taste in those 60 to $100 \%$ boar meat patties (perception in/for $60 \%$ tainted meat patties 
323 is significantly $(\mathrm{P}<0.05)$ higher compared to $40 \%$ ), and is preceded by the increased

324 perception of boar taint smell from $40 \%$ onwards (perception in $40 \%$ tainted meat 325 patties is significantly $(P<0.05)$ higher compared to $20 \%)$. It can be noted that these 326 observations were not as distinct for the patty with $100 \%$ of boar meat; i.e. general 327 tastiness was significantly higher $(P<0.05)$ compared to the 10 and $20 \%$ boar meat 328 patty, borderline significantly $(P=0.063)$ different from the $0 \%$ boar taint patty, but not 329 significantly different compared to the results for the $40 \%$ boar meat patty. This can be 330 attributed to an unforeseen scoring bias that can probably be explained by the aversion 331 of the experts towards boar taint; i.e. products that are tasted later on in the series 332 become subject to more stringent scoring by the experts and vice versa. In this 333 particular case, the $100 \%$ boar meat patties were tasted early on in the series on both 334 day 1 and 2 (despite randomisation), which should be avoided in future studies.

335 Overall, IND and SK levels in the trial 1 patties (fresh matter) were relatively low and 336 did not have or had little effect on boar taint perception. There was however a clear 337 rise in AEON concentration with increasing percentage of tainted boar meat (as can 338 be consulted in supplementary information table 9). Hence, combined with the results 339 of the sensory evaluation of the patties (discussed above), it would thus appear that a 340 product with more than approximately $400 \mu \mathrm{g} \mathrm{kg}-1$ AEON $(\approx$ levels in the $60 \%$ boar 341 meat patty (fresh matter), as reported in supplementary information table 9) is not acceptable and/or "consumable" due to the perception of boar taint.

\subsubsection{Trial 2}

345 Since the (meat from) boars that could be selected for trial 1 (supplementary 346 information table 6) did not demonstrate a very strong and/or combined taint (i.e. a 347 combination of IND, SK and/or AEON, as concluded based on chemical analysis), it 348 was decided to repeat the first trial with meat from more heavily tainted boars and/or 
349 boars with a combined taint (e.g. AEON and SK) in a second trial, for which patties

350 with $0,20,40$ and $60 \%$ of tainted meat (but not 10, 80 and/or $100 \%$ ) were produced.

351 Correlations between sensory parameters and scores in relation to boar meat 352 percentage can be consulted in supplementary information table 10, whilst the score 353 and ranking interpretation sheet can be consulted in supplementary information table 354 5. All trends are shown in figure 2, and detailed data can be consulted in 355 supplementary information table 11. IND, SK and AEON levels in trial 2 patties are 356 reported in supplementary information table 12.

357 In the second trial, general tastiness of patties was thwarted from $40 \%$ of mixing 358 onwards; i.e. there was no significant difference between 0 and $20 \%(P>0.05)$, but 35940 and $60 \%$ were judged less tasty $(P<0.05)$ in comparison to 0 and $20 \%$ of mixing. 360 The same trends could be observed regarding the appreciation of general smell, as 361 well as the perception of boar taint taste and smell; i.e. demonstrating a significant shift 362 and clear cut-off $(P<0.05)$ between 20 and $40 \%$. Depreciation of general taste was 363 more gradual, with a significant difference between 0 and $60 \%(P<0.05)$, but only a 364 trend for difference between 0 and $40 \%$, and between 20 and $60 \%(P=0.07)$.

365 Combining the results of the chemical analysis and sensory evaluation of trial 2 patties 366 (as discussed above), it would appear that a patty with more than $37 \mu \mathrm{g} \mathrm{kg}-1 \mathrm{SK}$ in 367 combination with $\pm 200 \mu \mathrm{g} \mathrm{kg}-1$ AEON ( $\approx$ levels in the $40 \%$ boar meat patty) is not 368 acceptable and/or "consumable" compared to respectively $29 \mu \mathrm{g} \mathrm{kg}-1$ and $67 \mu \mathrm{gg}$-1 $(\approx$ 369 levels in the $20 \%$ boar meat patty). Acceptable AEON levels in trial 2 were thus clearly 370 lower compared to trial 1 , which is most likely attributable to the concurrent presence 371 of SK and possible synergistic effects with AEON. Notably, work by Mörlein et al. has 372 previously hinted at the higher importance of SK compared to AEON (D. Mörlein et al., 373 2016) in light of consumer acceptance. Moreover, since the vast majority of consumers 374 can detect SK, but not all can perceive AEON (Bekaert et al., 2011), this is of even 375 higher relevance. 
3.2.3. General results and discussion for patties

378 The number of research papers that focus on the investigation of acceptable IND, SK and/or AEON levels in mixed/diluted products is limited. Furthermore, several studies 380 compare and discuss different percentages of mixing of meat with boar taint in different 381 products, but often without including detailed information on IND, SK and AEON 382 concentrations. Yet, acceptable levels of mixing greatly depends on the severity of the 383 taint; i.e. less mixing with meat from gilts and castrates will be required for carcasses 384 with a less severe taint compared to strong 'tainters'. In addition, quite often, another 385 level of complexity is added due to reporting of AEON, IND and SK levels in fat, but 386 not the product itself. Moreover, since product appreciation also depends on several 387 other factors like e.g. the type of meat product (incl. lean/fat ratio), cooking conditions 388 (cooked-in vs. open-cook procedure), context (at home vs. in a controlled 389 environment), serving temperature, consumer profile (age and gender, country of 390 origin, etc.), AEON (and SK and IND) sensitivity, and appreciation of the 'aroma' of 391 AEON, SK and/or IND, it has proven to be extremely difficult to establish clear boar 392 taint threshold levels (Aluwé et al., 2018; Bekaert et al., 2011; Blanch et al., 2012; Font393 i-Furnols, 2012; Font i Furnols, Gispert, Diestre, \& Oliver, 2003; Meier-Dinkel et al., 394 2013; D. Mörlein et al., 2016; Trautmann, Gertheiss, Wicke, \& Mörlein, 2014; Wauters 395 et al., 2017).

396 In light of the valorisation and marketing of tainted boar meat by mixing/diluting in 397 patties, the results of this study require further confirmation by consumer panels. Since 398 the average consumer will be less sensitive and/or strict compared to the average boar 399 taint expert (Lawless \& Claassen, 1993; D. Mörlein et al., 2016), we expect that the 400 acceptable levels of IND, SK and/or AEON will be higher in these conditions than is 401 reported here. Additional experimentation should deliver fine-tuning (e.g. additional 402 seasoning) and also unravel interaction and synergistic effects of AEON, IND and SK. 


\subsection{Restructured cooked ham}

405 Sensory characteristics of tainted ham prepared with brine without addition of a smoke 406 condensate (= 'control') was compared to tainted ham prepared with brine with added 407 Smokez LFBN or BN-9 to assess the boar taint reducing and/or masking potential of 408 the smokes. Results of the sensory evaluation of restructured cooked ham samples 409 following experimentation with the addition of smoke condensates to tainted boar meat 410 are discussed below and can furthermore be consulted in figure 3 and supplementary 411 information table 13 (score and ranking interpretation sheets can be viewed in 412 supplementary info. table 5).

\subsubsection{Ham tasted cold}

415 When tasted cold, general tastiness was significantly better for ham smoked with 416 Smokez LFBN compared to Smokez BN-9 and the control $(\mathrm{P}<0.05)$. Smokez BN-9 417 also delivered a tastier product compared to the control $(P<0.05)$, but the effect of 418 Smokez LFBN was far more pronounced, which was also reflected in ranking for 419 preference and scoring of overall acceptance, where Smokez LFBN outranked both 420 Smokez BN-9 and the control $(P<0.05)$. Both Smokez LFBN and BN-9 improved 421 general smell $(P<0.05)$, but only Smokez LFBN significantly improved general taste 422 compared to the control $(P<0.05)$. Perception of boar taint taste was significantly 423 lower in Smokez LFBN compared to Smokez BN-9 $(\mathrm{P}<0.05)$ as well as the control $(\mathrm{P}$ $424<0.05)$, and the same applied for Smokez BN-9 compared to the control $(\mathrm{P}<0.05)$. 425 Regarding the perception of boar taint smell, only Smokez LFBN delivered significantly 426 better results, with the smell being perceived less strongly in comparison to the control $427 \quad(\mathrm{P}<0.05)$. 


\subsubsection{Ham tasted warm}

430 In contrast to what was observed for cold serving and tasting, the use of Smokez LFBN 431 and $\mathrm{BN}-9$ did not significantly improve the tastiness of ham when tasted warm $(\mathrm{P}<$ 432 0.05). This was reflected in ranking for preference and scoring of overall acceptance, 433 for which none of the products outranked one or all others $(P<0.05)$. For Smokez 434 LFBN however, there was a significantly lower (better) ranking for boar taint compared 435 to the control $(P<0.05)$, whilst the effect on overall acceptance was borderline $(P=$ 436 0.09). This can be linked to a significantly lower perception of boar taint taste and smell 437 in Smokez LFBN ham compared to the control $(P<0.05)$.

\subsubsection{General results and discussion for ham}

440 Addition of smoke condensates to the brine partly concealed the taint in restructured 441 ham (with a preference for Smokez LFBN, then Smokez BN-9, compared to the 442 control). This demonstrates that the addition of smoke condensates to the brine can 443 reduce the perception of boar taint in restructured ham. Hence, in light of this, further 444 exploration of the use of other types of smoke and/or the use of aromas is 445 recommended, also including experimentation with raw cured-and-smoked ham.

446 As has been documented and reviewed previously, the process of cooking can 447 significantly reduce IND, SK and AEON levels in the cooked vs. the raw ham 448 (Engesser, 2015; Lundstrom et al., 2009). In the current study, the levels (in fresh 449 matter) dropped from an average concentration of $7.6 \mu \mathrm{g} \mathrm{kg}-1$ of IND and $70.2 \mu \mathrm{g} \mathrm{kg}-1$ 450 of AEON to an average of $4.5 \mu \mathrm{g} \mathrm{kg-1}$ IND and $40.4 \mu \mathrm{g} \mathrm{kg}-1$ AEON (there were no 451 detectable levels of SK (< LOD)); i.e. equaling a decrease of approximately $41 \%$ of 452 IND and $42 \%$ of AEON. This drop might be attributable to the process of cooking itself, 453 although it has been hypothesized that the addition of smoke may also aid in the 454 reduction of boar taint levels through interaction with IND, SK and/or AEON (Engesser, 
2015; Lundstrom et al., 2009). However, in the current study, the addition of smoke

456 did not appear to reduce actual IND, SK and/or AEON levels since the concentrations 457 of all 3 major boar taint compounds in different hams, including the control, was highly 458 comparable (with an average of $4,5 \mu \mathrm{g} \mathrm{kg}-1$ IND, 40,4 $\mu \mathrm{g} \mathrm{kg}_{-1}$ AEON and no detectable 459 levels of SK (<LOD)).

\subsection{Frankfurter sausages}

\subsubsection{Trial 1}

In the first trial, 8 different types of Frankfurter sausages were produced to assess the effect of the addition of different smokes and/or the effect of a different cooking temperature on boar taint perception. The results of the sensory evaluation of can be consulted in figure 4 and supplementary information table 14.

\subsubsection{Effect of different smokes}

469 None of the smoke condensates delivered a significant drop in boar taint perception and/or a significantly tastier product $(P>0.05)$ compared to the traditionally smoked

471 sausage (cooked at $72^{\circ} \mathrm{C}$ ). Nevertheless, boar taint taste in Rudinsmoke $\mathrm{C}$ sausages 472 was less pronounced in comparison to the other smokes $(P<0.05$ when compared to 473 Rudinsmoke $B, P=0.08, P=0.09$ and $P=0.08$ compared to Rudinsmoke $D$, Smokez 474 Poly C-10 and Smokez Supreme Poly C, respectively). To a limited extent, perception 475 of boar taint smell in Rudinsmoke $\mathrm{C}$ sausages was less prominent in comparison to 476 Rudinsmoke $B(P=0.09)$, Rudinsmoke $D(P<0.05)$, Smokez Poly $C-10(P<0.05)$ as 477 well as the traditionally smoked sausage $(P=0.08)$. Results of the chemical analysis 478 of IND, SK and AEON levels in the sausages did not reveal a link with the above 479 mentioned preferences and/or perception of boar taint (data not shown); i.e. the use 480 of a certain smoke condensate did not alter IND, SK and AEON concentrations, but, 481 apparently, only slightly altered their perception. 


\subsubsection{Effect of cooking temperature}

484 General tastiness of sausages cooked at $80^{\circ} \mathrm{C}$ was significantly higher compared to 72 , but not when cooked at $65^{\circ} \mathrm{C}$, and thus also preferred over 72 (ranked significantly better and scored higher $(P<0.05)$ compared to $\left.72^{\circ} \mathrm{C}\right)$, but not $65^{\circ} \mathrm{C}$. Nevertheless, the perception of boar taint taste and smell did not significantly differ for different cooking temperatures $(P>0.05)$, and hence the preference for sausages cooked at $80^{\circ} \mathrm{C}$ did not appear to relate to boar taint perception, but was most likely due to the formation of Maillard reaction products (Tamanna \& Mahmood, 2015).

\subsubsection{Trial 2}

493 The boars that could be selected in the first trial did not demonstrate a very strong 494 and/or combined taint (supplementary information table 6), and therefore it was 495 decided to partly repeat the first trial with meat from more heavily tainted boars and/or 496 boars with a combined taint (e.g. AEON and SK) in a second trial. In addition, in the 497 first trial, the sausages were tasted cold. However, since Frankfurters are most often 498 consumed hot, the Frankfurters were indeed tasted hot in the second trial. Since 499 cooking temperature did not affect boar taint perception in the first trial, it was decided 500 not to re-assess the effect of alternative cooking temperatures. Figure 5 depicts the 501 results for trial 2, whilst more details can be consulted in supplementary information 502 table 15.

\subsubsection{Effect of different smokes}

505 General tastiness of the Rudinsmoke C sausage was significantly better compared to 506 the 3 others $(P<0.05)$. This can, at least in part, be linked to a difference in the 507 perception of boar taint, for which there was a (borderline) significant difference with 508 Rudinsmoke $D$ for boar taint taste $(P=0.06)$ and smell $(P<0.05)$, and a borderline 
significant difference with Rudinsmoke Supreme Poly C $(P=0.06)$ with regard to boar

510 taint taste. The positive attributes of the Rudinsmoke $\mathrm{C}$ smoke condensate was also

511 reflected in a relatively high average overall acceptance of 7 out of 10 and high ranking 512 for preference (ranked $1 \mathrm{st}$ ). When comparing IND, SK and AEON levels in the different 513 sausages, there was no distinct difference (data not shown). Hence, it can be 514 concluded that the use of different smoke condensates affects boar taint perception, 515 but does not interfere with actual IND, SK and AEON levels.

\subsubsection{Effect of cooking}

518 In this trial, the effect of cooking on IND, SK and AEON levels was assessed by 519 comparing concentrations prior to and after cooking of the sausage. On average, the 520 Frankfurters contained $36.6 \mu \mathrm{g} \mathrm{kg}_{-1}$ IND, $74.4 \mu \mathrm{g} \mathrm{kg}{ }_{-1}$ SK and $425.5 \mu \mathrm{g} \mathrm{kg}_{-1}$ AEON (fresh 521 matter). Prior to cooking, however, the raw material contained $55.2 \mu \mathrm{g} \mathrm{kg}-1$ IND, 103.9 $522 \mu \mathrm{g} \mathrm{kg}-1 \mathrm{SK}$ and $596.6 \mu \mathrm{g} \mathrm{kg}-1$ AEON, which means cooking decreased IND, SK and 523 AEON concentrations with $34 \%, 28 \%$ and $29 \%$, respectively. In line with what was 524 already discussed for restructured ham, this decrease is likely to be the direct result of 525 the cooking process itself, although it might also be linked to the use of smoke through 526 interaction between IND, SK and/or AEON and certain smoke constituents (Engesser, 527 2015; Lundstrom et al., 2009). The latter has however, to the best of our knowledge, 528 not been studied in depth.

\subsubsection{General results and discussion for Frankfurter sausages}

531 Due to the relatively high fat content of the Frankfurter sausage, IND, SK and AEON levels in the final product were significantly higher in comparison to other pork products

533 like e.g. restructured cooked ham. Nonetheless, this did not result in the immediate 534 rejection of the sausage due to the perception of boar taint because, apparently, the 535 typical smoky aroma of the sausage could, at least in part, mask both orthonasal and 
536 retronasal boar taint odour. There was no clear advantage to the use of an alternative

537 cooking temperature or specific smoke condensates, expect for Rudinsmoke C.

538 Regarding the possible effect of cooking temperature on boar taint perception, it must

539 however be noted that any effect of temperature may have been overlooked because

540 of the sausages were tasted cold. Therefore, in follow-up research, the effect of

541 alternative cooking temperatures should be re-assessed following hot consumption.

542 Follow-up studies, including consumer tests, are also recommended to further

543 investigate the potential of traditional smoking, the use of smoke and other aromas for

544 the reduction/masking of boar taint in Frankfurters. Even more so since independent

545 research also points towards the noteworthy potential of smoking for masking of boar

546 taint perception in cooked sausages (Martinez et al., 2016). In contrast, colleagues

547 Aarlyng \& Koch, and Mörlein et al. objected to the potential of liquid smoke as a boar

548 taint masking strategy (Aaslyng \& Koch, 2018; J. Mörlein, Meier-Dinkel, Gertheiss,

549 Schnäckel, \& Mörlein, 2019), but it should however be taken into account that this may

550 be subject to boar taint level and type, as well as the type and concentration of liquid 551 smoke.

552 The results of the current study demonstrate that the addition of smoke might influence 553 product tastiness, and that the use of smoke condensates may aid in the reduction of 554 boar taint perception, like seems to be the case for e.g. Rudinsmoke C. In addition, the 555 cooking process itself likely contributes to the reduction of IND, SK and AEON levels 556 in comparison to the raw product. It should however be taken into account that these 557 findings and conclusions may be subject to the type of taint, which warrants follow-up 558 research.

559 Upon comparison of average IND, SK and AEON levels in patties, restructured cooked 560 ham and Frankfurter sausages in relation to general tastiness, it appears that higher 561 levels of IND, SK and AEON may be acceptable in Frankfurter sausages compared to 562 restructured ham and patties. Therefore, moving forward, the valorisation of meat with 563 boar taint in Frankfurters is a valid option, but which of course requires further 
564 confirmation by means of consumer tests. In this context, it would be of specific interest 565 to have a consumer panel compare the acceptability of the traditionally cooked 566 Frankfurter sausage compared to e.g. a Rudinsmoke C sausage and/or e.g. smoking 567 combined with the use of a certain mix of spices with sharp and warm pungent notes 568 (white pepper, mustard, nutmeg mace, coriander, small cardamom and sweet 569 marjoram), of which the boar taint masking potential has been reported previously 570 (Tamanna et al., 2015). The use of white pepper, cardamom and mace is of specific 571 interest for follow-up research since those 3 spices were also used in the current study. 572 
574 Different approaches for the valorisation of tainted pork appeared to be highly 575 promising; i.e. mixing with gilt raw materials in patties, processing into Frankfurter 576 sausages, as well as processing into restructured ham. Hence, it can be concluded 577 that fine tuning of production processes (use of cooking and/or smoke condensates)

578 and mixing with non-boar taint meat (targeted dilution) can significantly reduce (the 579 perception of) boar taint and thus potentially reduce rejection by consumers. Moving 580 forward, additional experimentation and consumer tests are needed to confirm these 581 results in a broader (non-trained) test group as well as to provide more boar taint 582 reducing and/or masking alternatives, like e.g. the use of aromas and marinades.

\section{ACKNOWLEDGEMENTS}

586 The authors would like to thank all members of the boar taint expert panel (from ILVO, 587 KUL \& UGent), as well as Dirk Stockx, Beata Pomian, Joke Goedgebuer and Mieke 588 Naessens (UGent) for their most invaluable contribution to this work. In addition, the 589 authors would also like to explicitly thank Liesbeth De Wilde (ILVO), Marijn Dhaenens 590 and Els Beda (Debra Meat) for their assistance in selecting the carcasses and meat 591 cuts.

592 This project was funded by the Flemish Government through the Agency for Innovation 593 and Entrepreneurship (VLAIO) and Flanders' FOOD (REDBOAR, HBC.2016.0501 and 594 HBC.2017.0103).

\section{Conflict of interest statement}

597 The authors declare that there is no conflict of interest. 
TABLES

600 Table 1: Overview of smoking types and methods for Frankfurter sausage (cooking

601 programs can be consulted in supplementary information table 2 and 3 ).

\begin{tabular}{|c|c|c|c|c|}
\hline Sausage & Type of smoke & Smoking method & $\begin{array}{l}\text { Cooking } \\
\text { program }\end{array}$ & $\begin{array}{c}\text { Cooking } \\
\text { temperature }\end{array}$ \\
\hline \multicolumn{5}{|l|}{ Effect of $t^{\circ}$} \\
\hline 1 & Beech wood chips & Traditional & 1 & $72^{\circ} \mathrm{C}$ \\
\hline 2 & Beech wood chips & Traditional & 1 & $65^{\circ} \mathrm{C}$ \\
\hline 3 & Beech wood chips & Traditional & 1 & $80^{\circ} \mathrm{C}$ \\
\hline \multicolumn{5}{|c|}{ Effect of smoking: } \\
\hline 4 & Rudinsmoke B & $\begin{array}{l}\text { drenching: } 90 \mathrm{~s} \text { in } \\
20 \% \text { solution }\end{array}$ & 2 & $72^{\circ} \mathrm{C}$ \\
\hline 5 & Rudinsmoke C & $\begin{array}{l}\text { drenching: } 90 \mathrm{~s} \text { in } \\
20 \% \text { solution }\end{array}$ & 2 & $72^{\circ} \mathrm{C}$ \\
\hline 6 & Rudinsmoke D & $\begin{array}{l}\text { drenching: } 90 \mathrm{~s} \text { in } \\
20 \% \text { solution }\end{array}$ & 2 & $72^{\circ} \mathrm{C}$ \\
\hline 7 & Smokez poly C-10 & $\begin{array}{l}1 \% \text { added to the } \\
\text { meat batter }\end{array}$ & 2 & $72^{\circ} \mathrm{C}$ \\
\hline 8 & $\begin{array}{l}\text { Smokez supreme } \\
\text { poly C }\end{array}$ & $\begin{array}{l}1 \% \text { added to the } \\
\text { meat batter }\end{array}$ & 2 & $72^{\circ} \mathrm{C}$ \\
\hline
\end{tabular}

602

603 
605 Figure 1: Observed trends (mean \pm std. error) for blending of boar taint meat in

606 patties in trial 1 , with scale to $150=$ 'very unpleasant' for general smell, $150=$ 'very

607 strong' for boar taint smell, 150 = 'very unpleasant' for general taste, 150 'very

608 strong' for boar taint taste, 150 = 'very tasty' for general tastiness.

609 Figure 2: Observed trends (mean \pm std. error) for blending of boar taint meat in

610 patties in trial 2, with scale to $150=$ 'very unpleasant' for general smell, $150=$ 'very

611 strong' for boar taint smell, 150 = 'very unpleasant' for general taste, 150 'very

612 strong' for boar taint taste, 150 = 'very tasty' for general tastiness.

613 Figure 3: Observed trends (mean \pm std. error) for restructured ham tasted cold

614 (above) and warm (below), with scale to 150 = 'very unpleasant' for general (G.)

615 smell, $150=$ 'very strong' for boar taint (BT) smell, $150=$ 'very unpleasant' for

616 general (G.) taste, 150 'very strong' for boar taint (BT) taste, 150 = 'very tasty' for

617 general (G.) tastiness.

618 Figure 4: Observed trends (mean \pm std. error) for Frankfurter sausages in trial 1,

619 with scale to $150=$ 'very pleasant' for general (G.) smell, $150=$ 'very strong' for boar 620 taint $(\mathrm{BT})$ smell, 150 = 'very pleasant' for general (G.) taste, 150 'very strong' for boar 621 taint $(\mathrm{BT})$ taste, 150 = 'very tasty' for general (G.) tastiness.

622 Figure 5: Observed trends (mean \pm std. error) for Frankfurters in trial 2, with scale to $623150=$ 'very unpleasant' for general (G.) smell, $150=$ 'very strong' for boar taint (BT) 624 smell, 150 = 'very unpleasant' for general (G.) taste, 150 'very strong' for boar taint 625 (BT) taste, $150=$ 'very tasty' for general (G.) tastiness. 
FIGURES

629

Figure 1

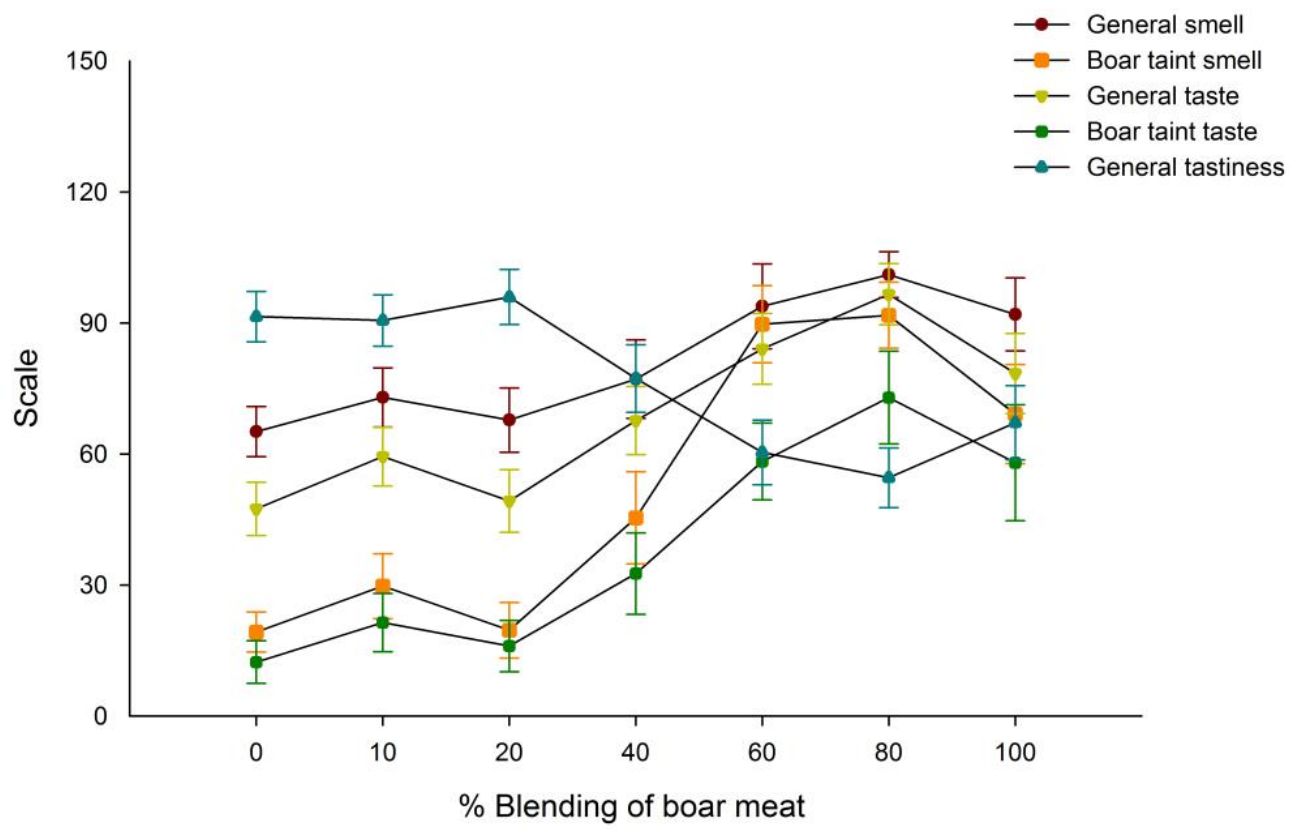

630

$631 \quad$ Figure 2

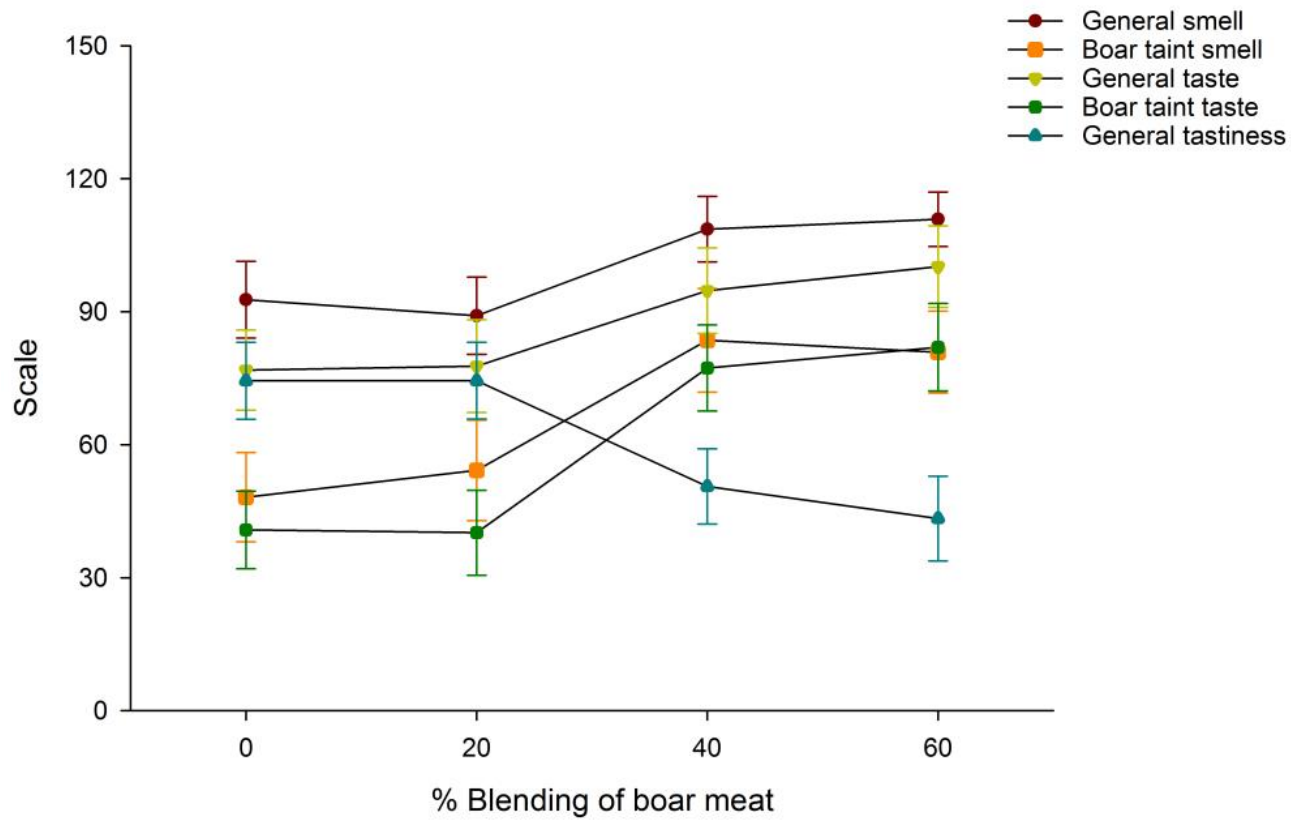

Figure 3 

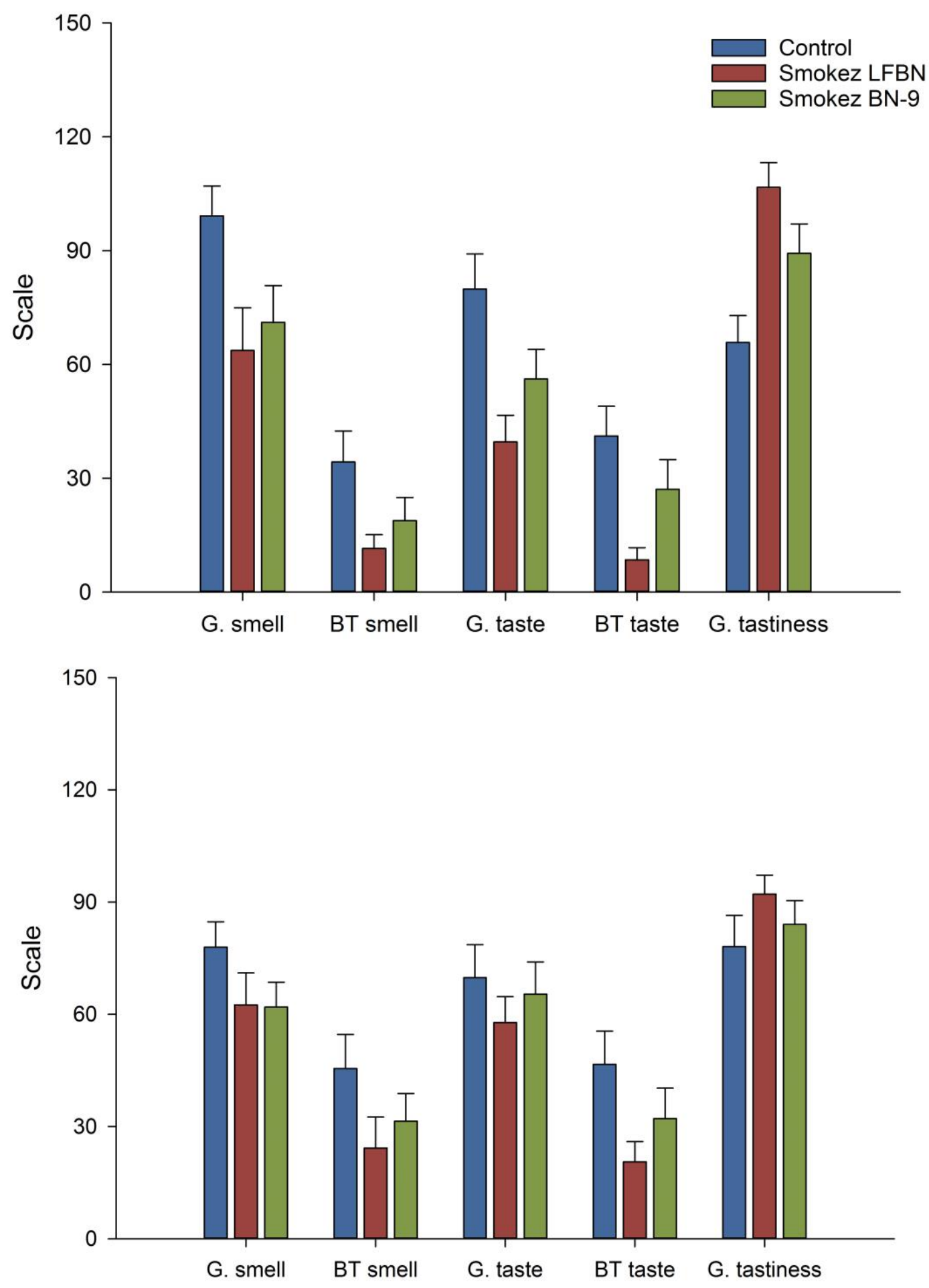

635 Figure 4 


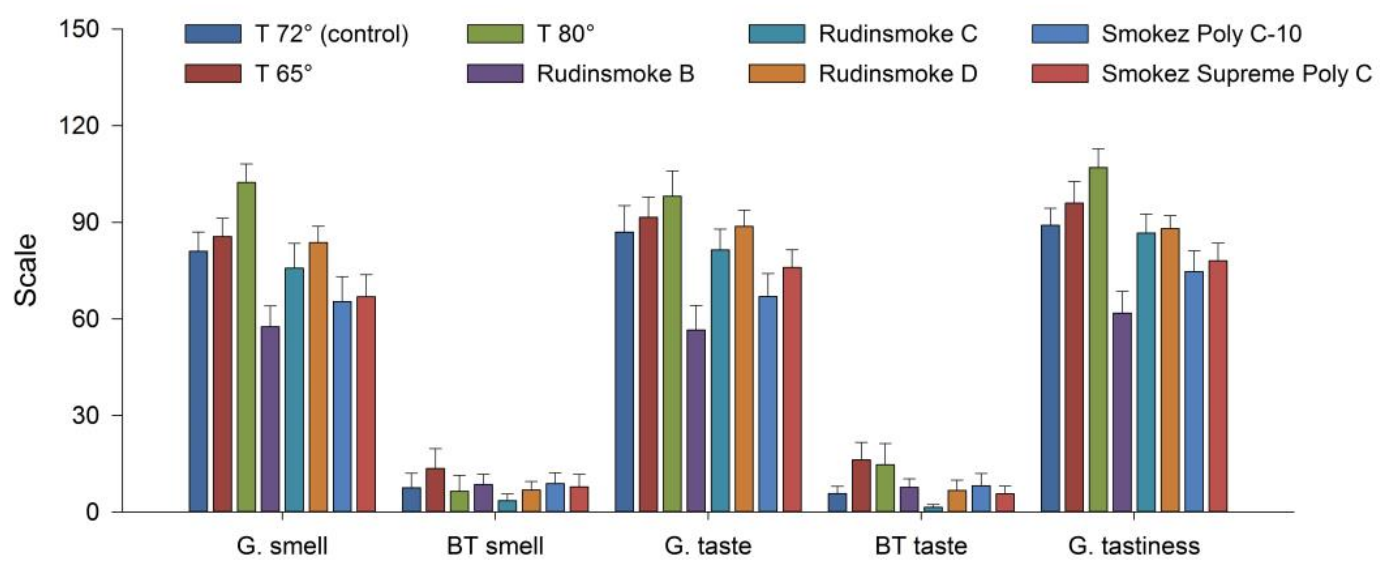

Figure 5

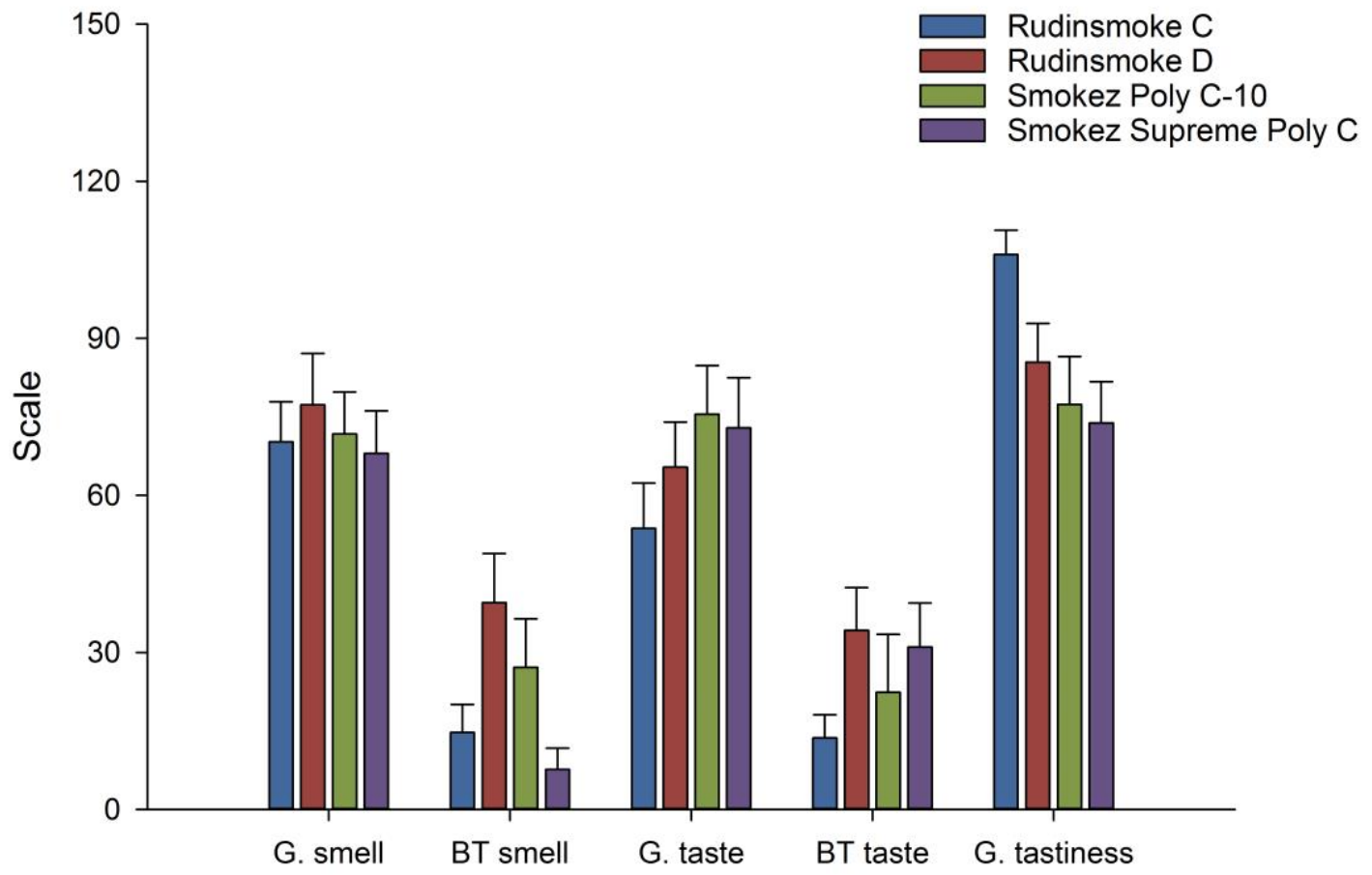

638

639 
642

643

644

645

646

647

648

649

650

651

652

653

654

655

656

657

658

659

660

661

662

663

664

665

666

667

668

669

670

671

672

673

674

675

676

677

678

679

680

681

682

683

684

685

686

687

688

689

690

Aaslyng, M. D., \& Koch, A. G. (2018). The use of smoke as a strategy for masking boar taint in sausages and bacon. Food Research International, 108, 387-395. https://doi.org/https://doi.org/10.1016/j.foodres.2018.03.069.

Aluwé, M., Aaslyng, M., Backus, G., Bonneau, M., Chevillon, P., Haugen, J. E., . . . Font-i-Furnols, M. (2018). Consumer acceptance of minced meat patties from boars in four European countries. Meat Sci, 137, 235-243. https://doi.org/https://doi.org/10.1016/j.meatsci.2017.11.034.

Aluwe, M., Millet, S., Nijs, G., Tuyttens, F. A., Verheyden, K., De Brabander, H. F., . . . Van Oeckel, M. J. (2009). Absence of an effect of dietary fibre or clinoptilolite on boar taint in entire male pigs fed practical diets. Meat Sci, 82(3), 346-352. https://doi.org/10.1016/j.meatsci.2009.02.001.

Aluwe, M., Tuyttens, F. A., \& Millet, S. (2015). Field experience with surgical castration with anaesthesia, analgesia, immunocastration and production of entire male pigs: performance, carcass traits and boar taint prevalence. Animal : an international journal of animal bioscience, 9(3), 500-508. https://doi.org/10.1017/s1751731114002894.

Babol, J., \& Squires, E. J. (1995). Quality of meat from entire male pigs. Food Research International, 28(3), 201-212. https://doi.org/https://doi.org/10.1016/0963-9969(95)93528-3.

Bekaert, K. M., Aluwe, M., Vanhaecke, L., Heres, L., Duchateau, L., Vandendriessche, F., \& Tuyttens, F. A. (2013). Evaluation of different heating methods for the detection of boar taint by means of the human nose. Meat Sci, 94(1), 125-132. https://doi.org/10.1016/j.meatsci.2013.01.006.

Bekaert, K. M., Tuyttens, F. A. M., Duchateau, L., De Brabander, H. F., Aluwé, M., Millet, S., . . . Vanhaecke, L. (2011). The sensitivity of Flemish citizens to androstenone: Influence of gender, age, location and smoking habits. Meat Sci, 88(3), 548-552. https://doi.org/https://doi.org/10.1016/j.meatsci.2011.02.010.

Bekaert, K. M., Vanden Bussche, J., Francois, S., Tuyttens, F. A., De Brabander, H. F., Vandendriessche, F., \& Vanhaecke, L. (2012a). A validated ultra-high performance liquid chromatography coupled to high resolution mass spectrometry analysis for the simultaneous quantification of the three known boar taint compounds. J Chromatogr A, 1239, 49-55. https://doi.org/10.1016/j.chroma.2012.03.060.

Bekaert, K. M., Vanden Bussche, J., Francois, S., Tuyttens, F. A., De Brabander, H. F., Vandendriessche, F., \& Vanhaecke, L. (2012b). A validated ultra-high performance liquid chromatography coupled to high resolution mass spectrometry analysis for the simultaneous quantification of the three known boar taint compounds. $J$ Chromatogr $A$, 1239, 49-55. https://doi.org/10.1016/j.chroma.2012.03.060.

Blanch, M., Panella-Riera, N., Chevillon, P., Furnols, M. F. i., Gil, M., Gil, J. M., . . . Oliver, M. A. (2012). Impact of consumer's sensitivity to androstenone on acceptability of meat from entire male pigs in three European countries: France, Spain and United Kingdom. Meat Sci, 90(3), 572-578. https://doi.org/https://doi.org/10.1016/j.meatsci.2011.09.018.

Claus, R., Weiler, U., \& Herzog, A. (1994). Physiological aspects of androstenone and skatole formation in the boar-A review with experimental data. Meat Sci, 38(2), 289-305. https://doi.org/10.1016/0309-1740(94)90118-x.

Engesser, D. J. (2015). Alternatives for boar taint reduction and elimination besides surgical castration and destroying testicular tissue. PhD Thesis. 
Font-i-Furnols, M. (2012). Consumer studies on sensory acceptability of boar taint: A review. Meat Sci, 319-329. https://doi.org/https://doi.org/10.1016/j.meatsci.2012.05.009.

Font i Furnols, M., Gispert, M., Diestre, A., \& Oliver, M. A. (2003). Acceptability of boar meat by consumers depending on their age, gender, culinary habits, and sensitivity and appreciation of androstenone odour. Meat Sci, 64(4), 433-440. https://doi.org/https://doi.org/10.1016/S0309-1740(02)00212-7.

Kallas, Z., Martínez, B., Panella-Riera, N., \& Gil, J. M. (2016). The effect of sensory experience on expected preferences toward a masking strategy for boartainted frankfurter sausages. Food Quality and Preference, 54, 1-12. https://doi.org/https://doi.org/10.1016/j.foodqual.2016.06.015.

Lawless, H. T., \& Claassen, M. R. (1993). Validity of Descriptive and Defect-oriented Terminology Systems for Sensory Analysis of Fluid Milk. Journal of Food Science, 58(1), 108-112. https://doi.org/10.1111/j.1365-2621.1993.tb03221.x.

Lundstrom, K., Matthews, K. R., \& Haugen, J. E. (2009). Pig meat quality from entire males. Animal : an international journal of animal bioscience, 3(11), 1497-1507. https://doi.org/10.1017/s1751731109990693.

Martinez, B., Rubio, B., Viera, C., Linares, M. B., Egea, M., Panella-Riera, N., \& Garrido, M. D. (2016). Evaluation of different strategies to mask boar taint in cooked sausage. Meat Sci, 116, 26-33. https://doi.org/10.1016/j.meatsci.2016.01.006.

Meier-Dinkel, L., Gertheiss, J., Schnackel, W., \& Morlein, D. (2016). Consumers' perception and acceptance of boiled and fermented sausages from strongly boar tainted meat. Meat Sci, 118, 34-42. https://doi.org/10.1016/j.meatsci.2016.03.018.

Meier-Dinkel, L., Sharifi, A. R., Frieden, L., Tholen, E., Fischer, J., Wicke, M., \& Mörlein, D. (2013). Consumer acceptance of fermented sausages made from boars is not distracted by respective information. Meat Sci, 94(4), 468-473. https://doi.org/https://doi.org/10.1016/j.meatsci.2013.03.031.

Mörlein, D., Trautmann, J., Gertheiss, J., Meier-Dinkel, L., Fischer, J., Eynck, H.-J., . . . Tholen, E. (2016). Interaction of Skatole and Androstenone in the Olfactory Perception of Boar Taint. Journal of Agricultural and Food Chemistry, 64(22), 4556-4565. https://doi.org/10.1021/acs.jafc.6b00355.

Mörlein, J., Meier-Dinkel, L., Gertheiss, J., Schnäckel, W., \& Mörlein, D. (2019). Sustainable use of tainted boar meat: Blending is a strategy for processed products. Meat Sci, $\quad 152, \quad 65-72$. https://doi.org/https://doi.org/10.1016/j.meatsci.2019.02.013.

Stolzenbach, S., Lindahl, G., Lundström, K., Chen, G., \& Byrne, D. V. (2009). Perceptual masking of boar taint in Swedish fermented sausages. Meat Sci, 81(4), 580-588. https://doi.org/https://doi.org/10.1016/j.meatsci.2008.10.013.

Tamanna, N., \& Mahmood, N. (2015). Food Processing and Maillard Reaction Products: Effect on Human Health and Nutrition. International journal of food science, 2015, 526762-526762. https://doi.org/10.1155/2015/526762.

Trautmann, J., Gertheiss, J., Wicke, M., \& Mörlein, D. (2014). How olfactory acuity affects the sensory assessment of boar fat: A proposal for quantification. Meat Sci, 98(2), https://doi.org/https://doi.org/10.1016/j.meatsci.2014.05.037.

Verplanken, K., Wauters, J., Vercruysse, V., Aluwé, M., \& Vanhaecke, L. (2017). Sensory evaluation of boar-taint-containing minced meat, dry-cured ham and dry fermented sausage by a trained expert panel and consumers. Food Chem, 233, 247-255. https://doi.org/https://doi.org/10.1016/j.foodchem.2017.04.105.

Wauters, J., Vercruysse, V., Aluwé, M., Verplanken, K., \& Vanhaecke, L. (2016). Boar taint compound levels in back fat versus meat products: Do they correlate? Food Chem, 206, 30-36. https://doi.org/https://doi.org/10.1016/j.foodchem.2016.03.031. 
Wauters, J., Verplanken, K., Vercruysse, V., Ampe, B., Aluwé, M., \& Vanhaecke, L. (2017). Sensory evaluation of boar meat products by trained experts. Food Chem, 237, 516-524. https://doi.org/https://doi.org/10.1016/j.foodchem.2017.05.128.

Wysocki, C. J., \& Beauchamp, G. K. (1984). Ability to smell androstenone is genetically determined. Proceedings of the National Academy of Sciences of the United States of America, 81(15), 4899-4902. 